Article

\title{
Visualized Co-Simulation of Adaptive Human Behavior and Dynamic Building Performance: An Agent-Based Model (ABM) and Artificial Intelligence (AI) Approach for Smart Architectural Design
}

\author{
Hwang Yi@ \\ Architectural Design \& Technology Lab, Department of Architecture, School of Engineering, Ajou University, \\ Suwon 16499, Korea; hwy@ajou.ac.kr; Tel.: +82-31-219-2493
}

Received: 25 June 2020; Accepted: 13 August 2020; Published: 18 August 2020

check for updates

\begin{abstract}
Human (occupant) behavior has been a topic of active research in the study of architecture and energy. To integrate the work of architectural design with techniques of building performance simulation in the presence of responsive human behavior, this study proposes a computational framework that can visualize and evaluate space occupancy, energy use, and generative envelope design given a space outline. A design simulation platform based on the visual programming language (VPL) of Rhino Grasshopper (GH) and Python is presented so that users (architects) can monitor real-time occupant response to space morphology, environmental building operation, and the formal optimization of three-dimensional (3D) building space. For dynamic co-simulation, the Building Controls Virtual Test Bed, Energy Plus, and Radiance were interfaced, and the agent-based model (ABM) approach and Gaussian process (GP) were applied to represent agents' self-learning adaptation, feedback, and impact on room temperature and illuminance. Hypothetical behavior scenarios of virtual agents with experimental building geometry were produced to validate the framework and its effectiveness in supporting dynamic simulation. The study's findings show that building energy and temperature largely depend on ABMs and geometry configuration, which demonstrates the importance of coupled simulation in design decision-making.
\end{abstract}

Keywords: architecture; building performance simulation; performance-based design; agent-based model; Gaussian process

\section{Motivation and Background}

\subsection{Performance-Based Design and Challenges}

In recent years, a heightened awareness of energy and sustainability in built environments has remarkably changed the ways in which we design, construct, and think about building. A number of collective commitments to account for energy efficiency and high performance in architecture have fostered significant progress in terms of building production concepts, manufacturing, and detailing. In this architectural shift, the development of digital tools incorporates computerized performance simulation into the design process [1,2], which plays a vital role in bridging the conventional divide between design and engineering in architecture. Yi and Yi [3] proposed an automated optimal three-dimensional space layout framework coordinated by performance simulation and simulated annealing. Lin and Gerber [4] suggested the use of a multi-objective genetic algorithm and performance simulation for generative building form-making workflows. The visualized representation 
of energy data, building geometry overlaid with colored radiance intensity, and the interoperability of thermal information and design workflow help architects to better understand the thermodynamic mechanisms of building systems and the active engagement of design in performance improvement.

By definition, simulation is the virtual execution of a model that engineers abstraction to specify the hierarchical structures or properties of physical reality [5]. In architecture, building performance simulation (BPS) can provide analytical insights into environmental design fitness, yielding predicted outcomes with a series of numerical data. Moreover, the BPS does not only provide the functional utility of scientific analysis but also offers sources of advanced architectural design. Simulation data can unveil hidden dimensions of design parameters and organize design vocabularies based on sustainability principles. Thus, this simulation-oriented design approach, so-called performance-based (or performance-driven) design (PBD), can help architects to conceive of building design as a successive process of informed decision-making. Recent developments in PBD-integrated building information modeling (BIM) have uncovered the possibility of creative design guidance in terms of morphological generation and allocation of various building elements. This refined process of sustainable building design emphasizes intelligent architects' orchestration, coordination, incorporation, and prediction of environmental factors in their work of form-making [6].

Nevertheless, it is not always possible to use PBD to rigorously maximize the performance of every inch of a building. In effect, BPS is a mathematical algorithm that emulates the real world. It must deal with a complex set of energy formulas and thermodynamic variables; thus, PBD inevitably produces some uncertainty in design parameters, scenarios, and geometry $[7,8]$. For example, (1) at the early design phases, many simulation input parameters (efficiencies of fan and motors, system sizing parameters, operation schedules, etc.) are largely approximated; (2) available weather files, remotely obtained from past observations, do not clearly represent local weather or surrounding microclimates; (3) in BPS modeling, uncertainty arises according to the way in which thermal zoning is configured [9], and complex geometry representation such as the non-uniform rational basis spline (NURBS) is not recognizable to building energy simulation (BES). For these reasons, BPS has some issues of diagnostic uncertainty and is sometimes unable to reveal design alternatives. Additionally, the opacity of the BPS workflow has significantly hindered the widespread use of PBD in architecture. Therefore, the application of conflicting simulation data must be properly and selectively addressed for the effective evaluation of competing design candidates. For conceptual or schematic design stages with insufficient building information, the PBD process must be as efficiently functional and supportive as possible to quickly guide architects in finding optimal design solutions.

\subsection{Co-Simulation: Design-Oriented BPS Platform}

Although the uncertainties of PBD may be unavoidable, we should try to close the gap between simulation and reality—or even create more realistic virtual outcomes than reality—by leveraging tighter data networking of heterogeneous datasets generated from different sources or introducing high-level computational control of simulation processes. In this attempt, preliminary data can be collected to localize environmental inputs while missing information can be estimated using the appropriate statistical methods or machine-learning techniques [8].

In terms of PBD, building is a highly complex and engineered environmental system; therefore, it is very challenging to evaluate all performance criteria simultaneously. The core engines of BPS are specialized for different purposes and require an understanding of heterogeneous algorithmic procedures. Thus, the use of a single simulator provides partial information. Co-simulation is a holistic approach that can overcome this issue via the modular composition of different simulators or the hybridization of algorithms [10].

Co-simulation is not a new idea. There have been many efforts to combine heterogeneous BPS components, subsystems, and algorithms towards a unified simulation scheme, and several techniques to exploit the interoperability of multiple simulations exist in the context of PBD processes [11-13]. Hansen [11] first attempted to synchronize computational fluid dynamics (CFD) and energy simulation 
based on the Gauss-Seidel feedback pattern. Wetter [12] developed a software environment named Building Controls Virtual Test Bed (BCVTB) that can activate user-driven external intervention in the simulation process. Hong et al. [13] suggested a cyber-physical system programming method based on the functional mock-up interface (FMI) that can be used in building information modeling (BIM).

The most straightforward of these techniques involves running existing simulators successively and making follow-ups on demand. This is more advantageous than real-time processing, but this method can become inefficient if it requires high-level expertise to interpret information and extra elaboration to put together different types of data in every iteration. An alternative approach is to create a design simulation platform, a sort of virtual environment enabling a collective exchange of data, models, criteria, and decisions based on a standard protocol for simulation interoperability. This does not intend to bifurcate the architectural process into design and analysis but rather to integrate information exchange through multipath input/output $(\mathrm{I} / \mathrm{O})$ control systems. This approach has the potential to widen the horizon of BPS' roles and functions extensively, increasing the flexibility of individual expert domains.

For architects and early-stage PBD, a co-simulation platform must serve to enhance design pursuits and PBD's process-driven workflow, where visual narratives of design and simulation become a design product. However, two major issues arise in this scheme: data synchronization and the development of information feedback loops. BPS is often overwhelmed by large quantities of data streaming, and design decisions may be misleading unless system models are appropriately defined. Excessively complex procedures to preprocess/refine building data may significantly delay the prototyping of design alternatives.

The resolution of performance analysis must be uniquely adjusted to intensify design power. Additionally, the organized reduction of complex variables to a set of parameters is necessary to quickly feed calculation results. These tactics must be able to synchronize all data flows in a unified automation process; thus, mathematical algorithms, data analytics, and parameters are blended in design pipelines.

Similar design-integrated approaches to PBD have been studied under the names of building information modeling (BIM) and computer-assisted design (CAD) systems [14-16]. However, most existing studies employ design simulation to retrofit existing buildings rather than to create new buildings from scratch. Funneling large amounts of data in different formats and streamlining algorithms and simulation engines into a few select design parameters as design agents are key in seamlessly interweaving design automation, rapid simulation, and optimal decision-making. The successful regulation of a synchrony of simulators through an agent-based architectural platform is promising for iterative PBD analysis and solution-seeking. Detailed performance analytics can enable the unified and rapid interconnection of design and analysis.

\subsection{Agent-Based Model ( $A B M)$ for PBD}

Known also as agent-based simulation (ABS) or individual-based modeling (IBM), the ABM is a computational method for modeling and analyzing complex systems and processes such as cellular structures, human cognition, or market networks of suppliers and buyers. "Agent" is anything that refers to a discrete model entity (or a rule/attribute-based actor) involved in changing a system's organization, appearance, or phenomena [17]. Based on system design, this could be a single person, a cell, a product, or any other entity engaged in system dynamics [18]. Each agent operates in a system with specific attributes and behavioral rules. ABM is a bottom-up approach because it is usually employed to examine overall system change by configuring autonomous individual actions and agents' decisions at a microscopic level. In particular, if a governing function or norm-authorizing system control is unclear and difficult to observe, this approach provides an effective solution to examine the collective impact to a system as a whole.

An ABM is comprised of three components: (i) agents (humans), (ii) a set of rules defining agent behavior, and (iii) a set of model setup parameters (a framework for simulation). Each of 
these is interrelated to assist in the construction of different model layers or a network of functional modules. In this regard, ABM is a very natural representation of a real system because actual, real-world phenomena are often convoluted, heterogeneous, and challenging to define with some regulatory parameters.

ABM has been applied widely across various areas, e.g., biology, urban planning, social science, and economics, to name a few $[19,20]$. In architecture and related areas, the ABM or agent-based approach benefits simulating human-building interactions, as it is able to deal with many arbitrary interventions engaged in dynamic behavioral relationships in terms of the effect-to-cause reasoning [21]. Lee and Malkawi [22] proposed a multi-agent model framework of energy-conscious building occupant behavior, and space syntax analysis (SSA) coupled with human agent simulation was found to be effective to characterize the interaction between human behavior and the physical setting of built environments $[23,24]$. Nevertheless, it is still challenging to incorporate ABM seamlessly into the architectural design process, especially in terms of the generative design of performance-based adaptive building geometry. It is noticeable that Gao and Gu [25] suggested agent simulation at a building level, and Andrew et al. [26] attempted to model spatial occupant behavior in a building plan regarding artificial lighting control. However, in most building studies, use of ABM targets the application of mechanical systems and energy use. SSA is mainly adopted on urban scales, exposing some limits in that it supposes completely purposive human movements and their complete knowledge of where they traverse in a static environmental context $[22,24,27]$. There are few or no ABM studies that attempt to address architects' concerns about PBD, i.e., generative geometry design, dynamic performance simulation, and visualized representation of process and outcomes [28].

\section{Simulation of Human Behavior and Adaptive Geometry}

\subsection{Simulation of Human Behavior in PBD}

Human behavior is a moving target for architectural design and among one of the most immediate yet uncertain factors in PBD. Thus, many researchers have worked hard to incorporate behavioral influences and parameters into design and analysis. For instance, the work of Breslav et al. [29] presented a visualization of occupants' spatial movements as well as their perception patterns through digital building modeling. Nagy et al. [30] leveraged crowd simulation techniques and space syntax to develop a generative space layout method. Moreover, there is growing recognition in the study of BPS that occupant behavior is a dominant component of building energy use [26,31-33].

Unfortunately, owing to the gaps in research between the fields of architecture and engineering, few PBD studies focusing on a unified approach to human behavior for both design and simulation have been published. Although there has been significant agreement on the need for behavior-centric approaches to building sustainability in architecture [34], human behavior has yet to be fully elucidated in the practice of PBD. Architects primarily seek to represent human activities and their spatial positioning graphically, and their impact on building energy and thermal comfort has not been fully explored via simulation. In contrast, on the BPS side, only the operation schedules of mechanical systems account for human behavior. Engineers focus on non-visual and numerical representations of occupants, which requires a certain level of scientific expertise. At any rate, an adaptive behavioral response to improve thermal comfort and the variability of space geometry to environmental changes has not been fully considered for the general performance assessment process and formal design development.

Therefore, human behavior modeling for PBD raises cross-disciplinary issues. PBD should be extended to be able to associate behavior-driven building system operation with geometry design and space allocation. Although it is challenging to predict bodily motion due to its random (unreasoned) nature, some habitual behavior scenarios of indoor space use can be established based on a situation-specific survey (of occupants' preferences, energy consumption patterns, and so on) for the purpose of design simulation. At the same time, the ambiguity of quantitative modeling must be 
clarified with performance-related behavioral definitions so that PBD results regarding sustainability are not biased.

\subsection{Visualized Simulation of Adaptive Building Geometry, Design Automation, and Optimization}

Generative adaptive form-making in PBD should be fueled by a clear strategy to build up robust data feedback for design automation and optimization. Performance criteria, environmental constraints, and design criteria must be coherently programmed/scripted in a visualized parametric design simulation framework $[35,36]$. For the full integration and automation of this framework in architectural design practice, this study employs the visual programming language (VPL) of Grasshopper (GH) for Rhino ${ }^{\circledR}$ (Robert McNeel \& Associates, USA), which is among the most popular and widely-used pieces of digital architecture software, to configure an automatic form-making process driven by BPS and optimization. Using this tool, adaptive design candidates are populated using built-in GH components and Phyton (IronPython) scripts, according to a predefined optimization convergence rule and fitness that represent BPS results. The VPL-based PBD offers a flexible design simulation mock-up for both architects and analysts because their functions and systems can be customized as necessary and compiled to create new language components. GH-VPL modules with scripted feedback loops to control data flow can offer a synchronous workflow of geometry modeling, simulation, and optimization. Results can then be used promptly to update design solutions and performance analysis reports. For large projects with heavy computational loads, data storage can be aided by sharing cloud servers, data networking, or adopting parallel computing techniques. Recent developments of GH-VPL provide an advanced programming environment through the Python editor, and scientific data processing techniques served by Python libraries and packages, such as multi-objective optimization or machine-learning algorithms, can be adapted to visualized design process, which will eventually make the design process more intelligent and produce high-quality PBD solutions.

\section{Materials and Methods}

\subsection{Scheme of PBD Automation}

Figure 1 represents the early-phase architectural PBD framework proposed in this study. This scheme features an experimental design simulation integrated environment to support virtual real-time energy monitoring and reporting of BPS results. The developed computational platform is targeted at an initial phase of architectural projects, where users (architects) need to rapidly compare different building forms. Users can visually identify how dynamic formal changes of space potentially influence human behavior (space occupancy) that is actively engaged in energy-efficient operation and, conversely, how they work to optimize building forms interactively. This framework intends to support flexible and user-friendly building design practice through VPL, enabling the immediate visualization of the evolution of building geometry and behavior. Based on this workflow, GH-VPL can be further customized for different occupancy scenarios. In the suggested workflow, ABM and the artificial intelligence (AI) of the Gaussian process offer an algorithmic solution for behavior modeling that ensures the uninterrupted involvement of heterogeneous data sources in the streamlined form-finding process (Figure 1). 


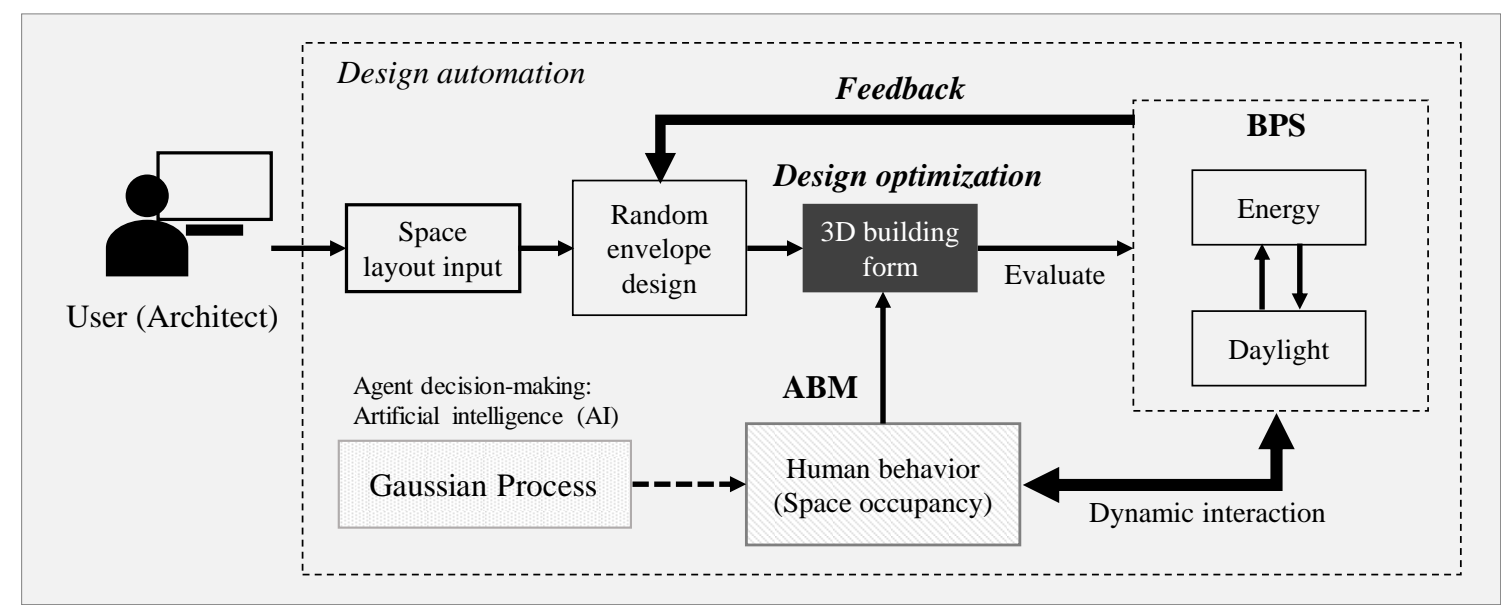

Figure 1. Scheme of ABM-based PBD automation process.

\subsection{Development of a Visual User Interface (VUI)}

The VUI was made with a VPL and GH and integrated with a BPS engine, EnergyPlus (EP), and an ABM model (Figures 2-4). It features a dashboard, geometry generation component, and integration of AI modeling using Python. The GH, one of the most popular VPLs in architecture, provides a graphic icon editor for the parametric building design process. Since this is a plugin of the CAD tool that supports complex geometric manipulation, it enables the design-oriented modeling of complex building systems as well as customized specification of the form-making process according to parameters set by designers. It also makes it possible to establish a seamless comprehensive model of computation through the co-simulation of a number of distinct analysis tools. However, despite such GH versatility in tool integration, it essentially offers a single option when it comes to data flow control. A scripted process is executed a single time through a synchronous data pipeline whenever an input parameter is available. To facilitate data-loop communication and multithread processing among different modules, a data flow director was coded using Python. This data flow director can control data connection and pathways by scheduling the rate of exchange. Data from external programs are stored in a CSV format, and the director commands an input module indicating when and how to read the data.

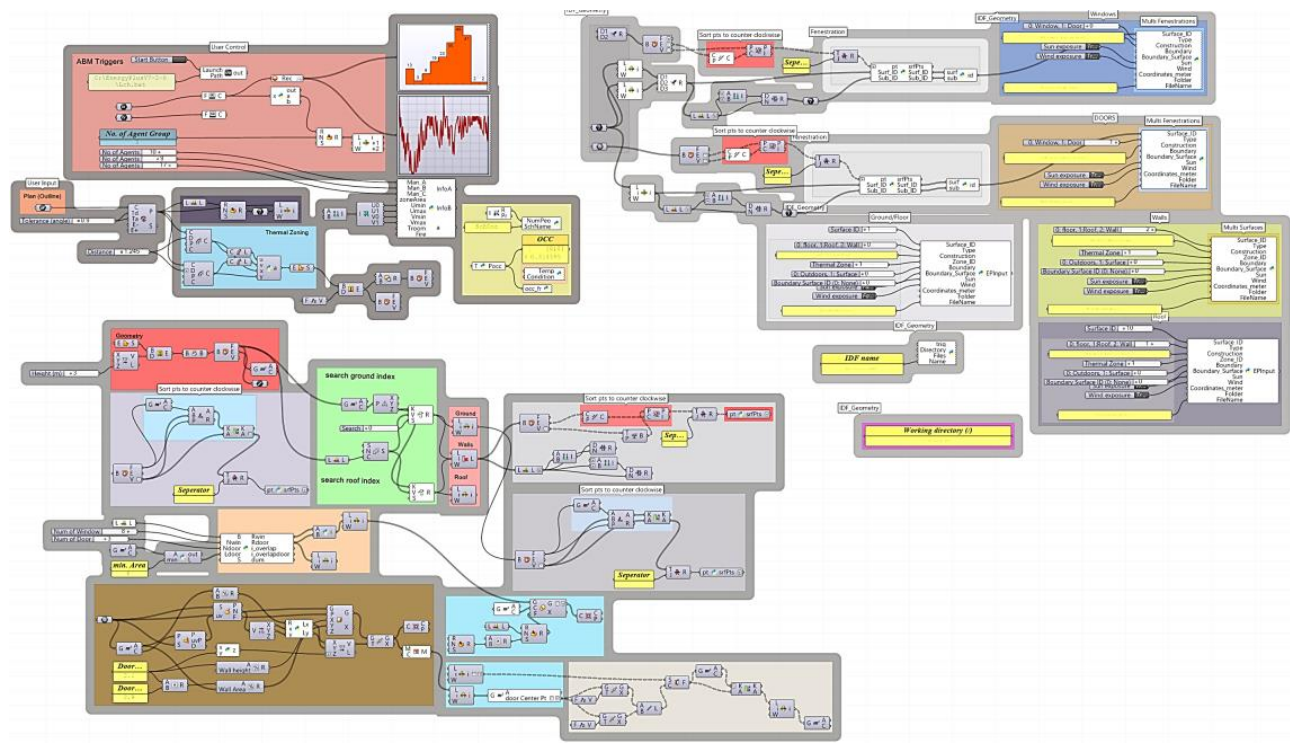

Figure 2. The whole VUI. 


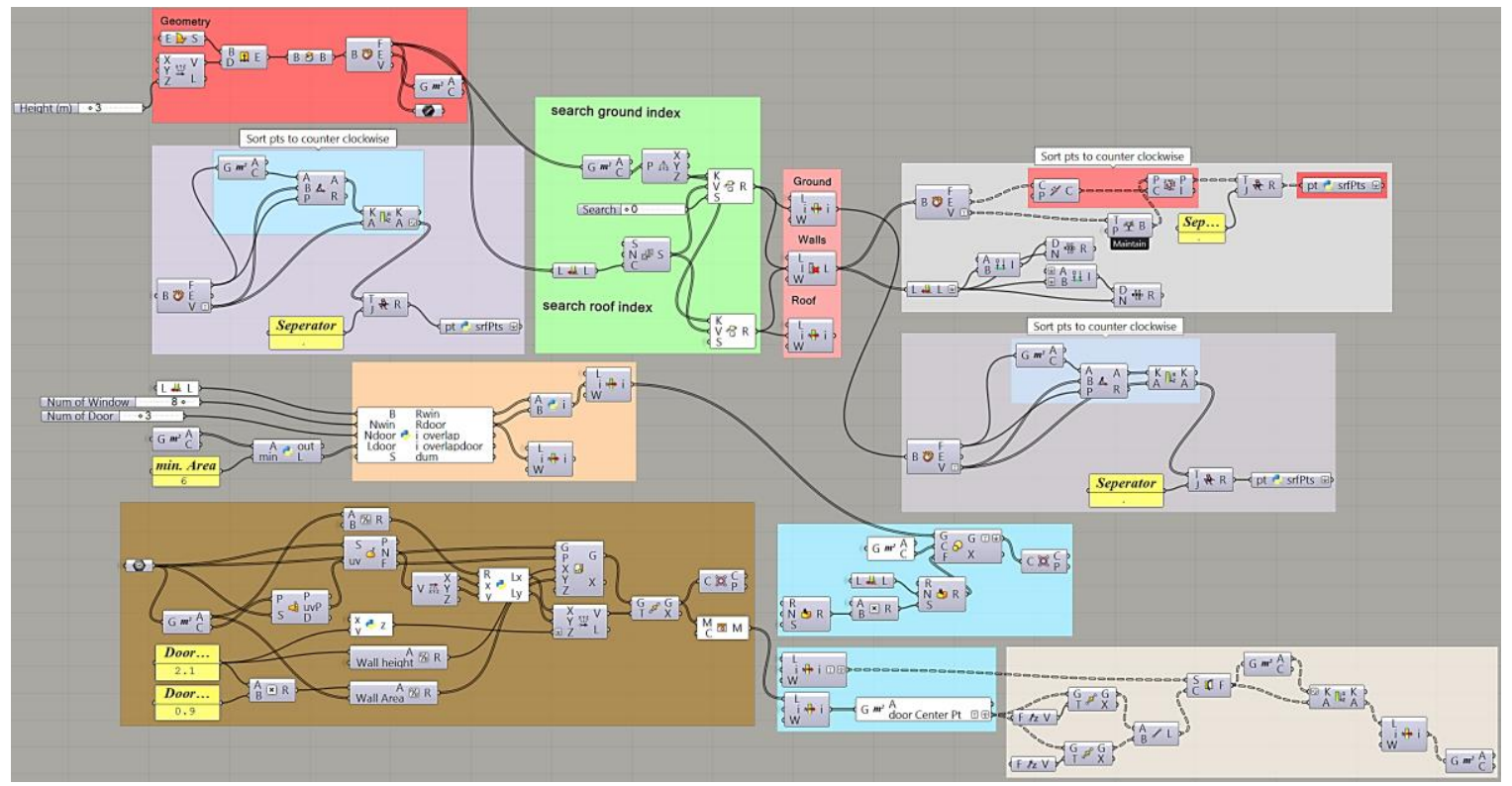

Figure 3. VUI: geometry generation and ABM component.

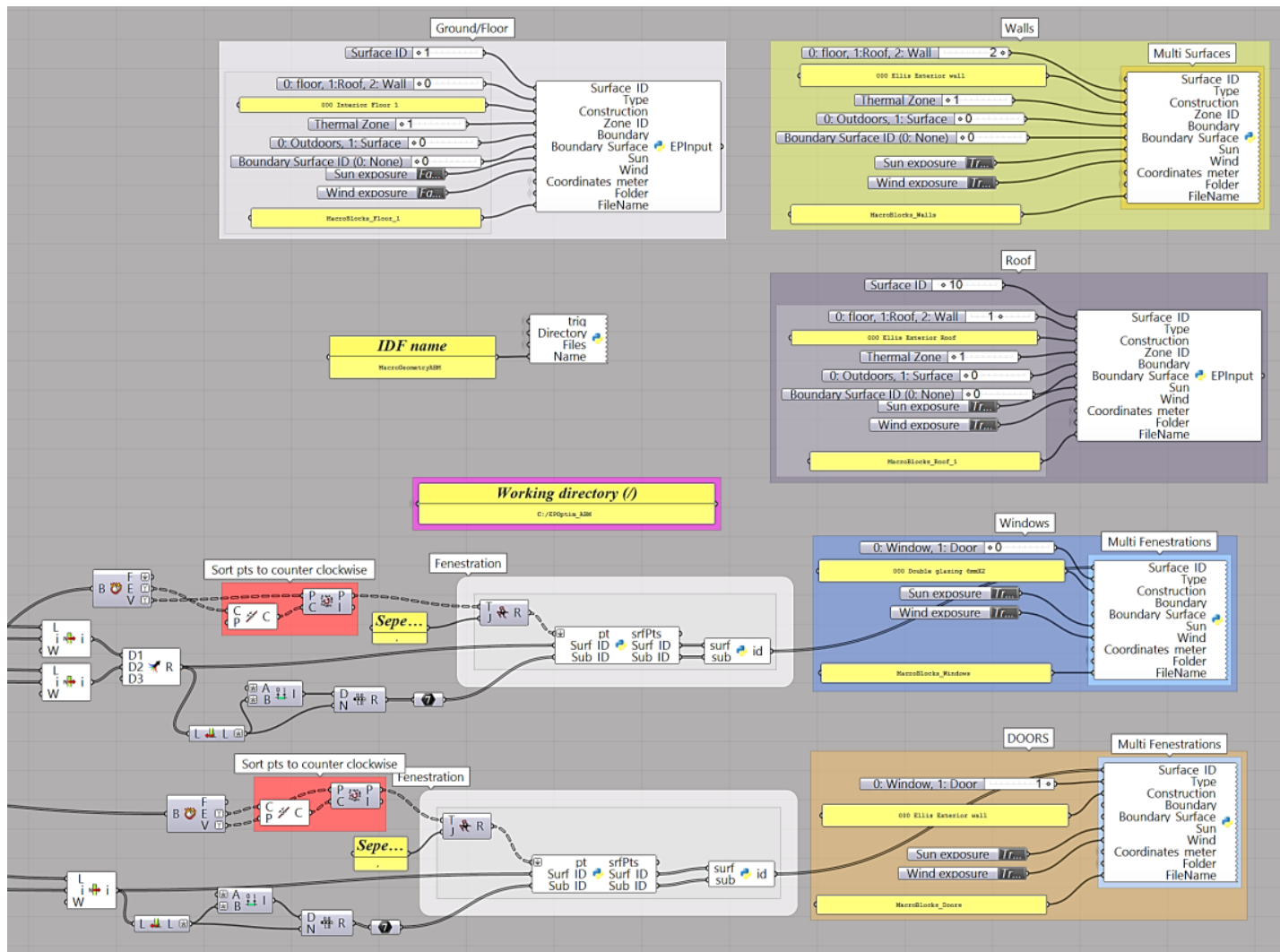

Figure 4. VUI BPS component: conversion of geometry data to EP format and writing an EP input file in .idf.

BPS coupled with automatic form-testing is used to evaluate energy use and daylight space in buildings. Although it is a critical component to gain environmental information on occupant feedback, there is a significant limitation in the use of EP for this purpose because EP's basic simulation setting is inflexible. More specifically, it runs all the way through once a simulation begins according 
to the initial setup. Thus, it informs design only once when each simulation run is done over a specific period, not responding to parameter variation during each time window.

EP supports external intervention on some simulation parameters while in a run through an extended setting. Accordingly, the BCVTB was encoded in this VPL interface (Figure 2). Once the user draws a curve or a polyline in Rhino as a building footprint outline, which is the most primitive input in the earliest design phase, the interface recognizes it. A building form generated with random fenestration (windows and doors) over exterior walls is converted to an EP geometry input format. Then, the script automatically triggers EP simulation and BCVTB. This initialization generates human figures in different positions, and the process visualizes the adaptive evolution of a building form and occupant behavior to optimize the form and energy use. Finally, a graphic dashboard is installed to present real-time simulation results.

\subsection{ABM Development for Space Occupancy and Cognitive Agent Behavior}

In this study, agents represent rational human building occupants that randomly belong to one of three social categorizations, Group A, B, and C, and each agent group has its own behavioral characteristics according to predefined attributes influencing energy-related building operation and room occupancy.

The studied ABM consists of four behavior-response modules: (i) social cognition, (ii) thermal response, (iii) positioning in space, and (iv) reaction. An agent's attributes are represented in two different condition-action (RA) layers that respectively characterize (i) preferences in terms of room occupancy and social interactions and (ii) thermal sensation and controllability. For the first RA layer, the following set of specific agent rules (R.1 R.6) is set to program agents' cognitive behavior.

(R.1) Most agents in Group A like to stay around corners.

(R.2) Group A and B have an affinity with each other. Agents in these groups would stay around together.

(R.3) Group B would not like to stay with C.

(R.4) Most agents in Group A prefer to stay inside in the morning (7 a.m. to 12 p.m.).

(R.5) Most agents in Group B do not like to stay around doors.

(R.6) Most agents in Group C prefer to stay around windows.

Agents think, act, and decide based on these reflex rules. Basically, they are self-cognitive, but those within the same group are not supposed to communicate to one another. Individual decisions of agents made by the condition-action rule take on collective behavior in space. For mathematical modeling, we find that the rule definitions involve some ambiguity in their language, such as "most" or "prefer". It is almost impossible, admittedly, to specify different personal preferences or mindsets uniformly without any uncertainty. That said, to make this design experiment as scientifically rigorous as possible, some rules are described with probabilistic formulas in ABM encoding. Assuming that a degree of compliance with the rules is normally distributed, our belief in specific behaviors depends on random variables. Per execution of rule (4), (5), and (6), a random number from 0 to 1 is sampled before positioning an agent. "Most" signifies that an agent will act if the random number is within the interquartile range (IQR, middle 50\%). Within this VPL interface, the behavior rules are integrated with geometry optimization. During BPS, all the information gained from the ABM is fed into a form optimization process. This experiment employed adaptive pattern-search hybridized simulated annealing (T-APSSA), which can locate a global optimum in a discrete search space within a smaller number of iterations compared to SA or generic algorithm (GA) [37]. The pseudocode (Figure 5) shows how optimization geometry is obtained in conjunction with the simulation of the ABM-based human-building interaction. 


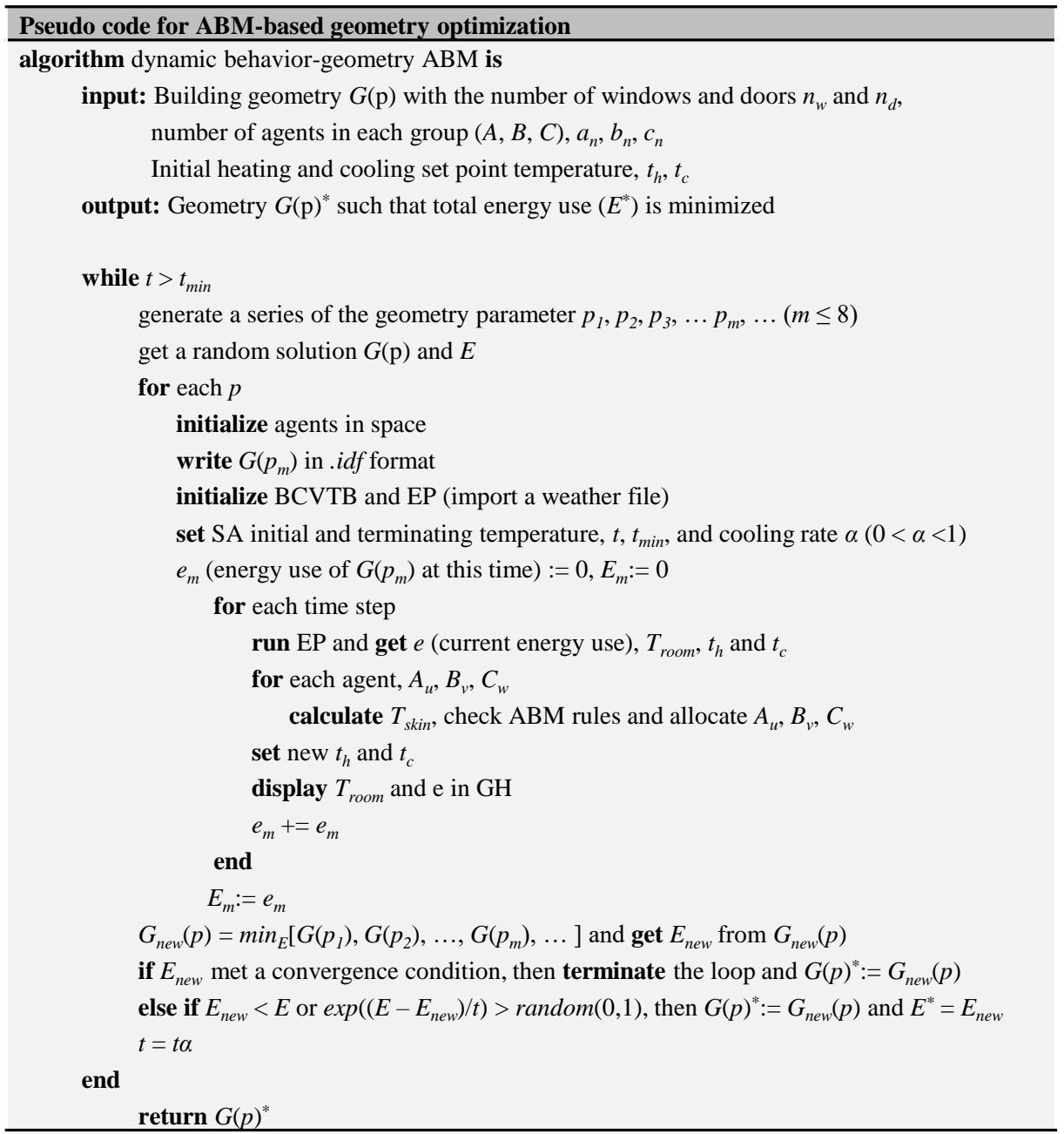

Figure 5. Pseudocode of ABM-based building form optimization.

Moreover, for the second RA layer, we assumed that every agent has its own thermosensitivity. Each individual is likely to have a different optimal level of thermal comfort. To explore how agents' thermal senses influence space temperature change and energy use, we added the following thermal control scenarios (S.1 S.3).

(S.1) Air-conditioning systems operate from 8 a.m. to 6 p.m. During operation, building users have full access to thermostat control. The systems are designed to have dual set points for heating and cooling.

(S.2) Group A is sensitive to slight over-heating. If their skin temperature increases above $33^{\circ} \mathrm{C}$, and the ratio of the number of Group A agents to total occupants is greater than 0.5 , the agents will change the set point temperature of the cooling equipment to $28^{\circ} \mathrm{C}$.

(S.3) Group $\mathrm{C}$ is sensitive to over-cooling. If their skin temperature drops below $32^{\circ} \mathrm{C}$, the cooling equipment will be turned off.

These scenarios were tested in a hot local climate (Miami, USA) using an electric heat pump with 14 seasonal energy efficiency ratios (system sizing was automatically set by EP). Agent action along with the random fenestration design of a room shape produced different thermal environments. The adaptive space thermal environment was monitored every $15 \mathrm{~min}$, which is the time step subject to the resolution of EP simulation. Realistically estimating personal thermal sensation involves a highly complex physical relationship between various factors such as air velocity, humidity, and radiation, among others [38]. As a design game, this experiment set a limit on complexity, focusing more 
intensely on the relationship between room geometry and occupant behavior. Skin temperature $\left(T_{\text {skin }}\right)$ was estimated as an average temperature of local body parts and represented by personal clothing insulation level $(\mathrm{clo})$ and zone mean air temperature $\left(T_{\text {room }}\right)$, such that $T_{\text {skin }}=\left[\left\{(0.155 \mathrm{clo}+0.115) T_{\text {room }}+\right.\right.$ $3.795\} /(0.155 c l o+0.23)$ ] [39]. To render this formulation as a stochastic characteristic of each agent, clothing level was represented approximately with probabilistic distribution (normal), setting other simulation parameters to constant values (Table 1).

Table 1. Behavior-related BPS input factors $[6,40]$.

\begin{tabular}{cccc}
\hline \multicolumn{3}{c}{ Clothing Insulation Level (clo) } & \\
\hline & $\mu$ & $\sigma$ \\
\hline Summer: day & 0.32 & 0.08 \\
Summer: night & 0.15 & 0.05 \\
Winter: day & 0.9 & 0.09 \\
Winter: night & 1.38 & 0.11 \\
\hline \multicolumn{2}{c}{ Auxiliary Parameters } & & \\
\hline & Base & Min. & Max. \\
Lighting power: general $\left(\mathrm{W} / \mathrm{m}^{2}\right)$ & 13 & 11 & 15 \\
Lighting power: intense $\left(\mathrm{W} / \mathrm{m}^{2}\right)$ & 15 & 11 & 19 \\
Appliance density $\left(\mathrm{W} / \mathrm{m}^{2}\right)$ & 15 & 12 & 22 \\
Occupant metabolic rate $(\mathrm{W})$ & 80 & 70 & 130 \\
\hline
\end{tabular}

\subsection{Agent Positioning Model: Gaussian Process Classifier}

In this ABM framework, we assumed that agents are active and intelligent enough to find the best spatial positions for themselves. They are short-memory entities characterized by the Markov property. Individuals remember their specific spatial positions at a present time step and use them to move to the next place. To make decisions about their own movements, agents use a Gaussian process classifier (GPC) to identify positioning suitability based on the information of geometrical room characteristics and other agents' space occupancy.

The Gaussian process (GP) is a machine-learning extension of the multivariate Gaussian in which the probability function values correspond to random output. GP assumes that the output data are jointly normally distributed using a non-parametric Bayesian model. Posterior inference is made without prescribed model parameters but only by random functions drawn from the prior. GP makes sense in cases where it is likely to assume normally distributed data association for inference, especially when predictions must be made with little information about data.

Suppose that we have a dataset $D$ of $n$ observations, $D=\left\{\left(x_{p}, f_{p}\right) \mid p=1, \ldots, n\right\}$, where $x$ is a $m$-variate input vector, $x \in \mathbb{R}^{n \times m}$ and $f \in \mathbb{R}^{n}$ denotes a target output from a function $f(x)$. Given the training dataset, GP would make a prediction for a new input $x_{*}$. The joint distribution of the training outputs, $f$, and the test outputs, $f_{*}$, is represented using the covariance matrix, $K$, such that

$$
\left[\begin{array}{l}
f \\
f_{*}
\end{array}\right] \sim N\left(\mathbf{0},\left[\begin{array}{cc}
K & K_{*}^{T} \\
K_{*} & K_{* *}
\end{array}\right]\right)
$$

where $y=f(x)$ and $y_{*}=f\left(x_{*}\right)$, and $K=K(X, X), K_{*}=K\left(X_{*}, X\right), K_{* *}=K\left(X_{*}, X_{*}\right)$. For $x$, the three types of covariance matrices are defined by

$$
\begin{gathered}
K=\left[\begin{array}{ccc}
k\left(x_{1}, x_{1}\right) & \cdots & k\left(x_{1}, x_{n}\right) \\
\vdots & \ddots & \vdots \\
k\left(x_{n}, x_{1}\right) & \cdots & k\left(x_{n}, x_{n}\right)
\end{array}\right] \\
K_{*}=\left[\begin{array}{ccc}
k\left(x_{*}, x_{1}\right) & \ldots & k\left(x_{*}, x_{n}\right)
\end{array}\right], K_{* *}=k\left(x_{*}, x_{*}\right)
\end{gathered}
$$


where $k$ is the covariance or kernel function used to evaluate the similarity between data points. The kernel is the core ingredient of GP and what makes it different from the general multivariate normal distribution. Rather than relying on a linear product of the deviations of input pairs $x$ and $x_{*}$ GP calculates joint probability or covariance by mapping it into implicit feature space using kernel functions. One of the most frequently used GP kernels is the squared exponential, also known as the radial-basis function $(\mathrm{RBF})$,

$$
k\left(x, x_{*}\right)=\sigma_{f}^{2} \exp \left(\frac{-x-x_{*}^{2}}{2 l^{2}}\right)
$$

where $x-x_{*}^{2}$ is the squared Euclidian distance between the two feature (input) vectors, $l$ is the length scale, and $\sigma_{f}$ is the variance of the output $f$. In the kernel, $\sigma_{f}$ is a scale factor by which the covariance is limited to $\sigma_{f}^{2}$ at maximum. For multivariate input, a kernel value between two vector points can be obtained by

$$
k\left(\boldsymbol{x}_{u}, \boldsymbol{x}_{v}\right)=\frac{1}{m} \sum_{i=1}^{m} \sum_{j=1}^{m} k\left(x_{u i}, x_{v j}\right), \quad \forall u, v \in\{1, \ldots, n\}
$$

From (1) and (2), the conditional probability of $y_{*}$ given $y$ is expressed as

$$
y_{*} \mid \boldsymbol{y} \sim N\left(K_{*} K^{-1} y, \quad K_{* *}-K_{*} K^{-1} K_{*}^{T}\right)
$$

with $\overline{y_{*}}=K_{*} K^{-1} \boldsymbol{y}$ and $\operatorname{var}\left(y_{*}\right)=K_{* *}-K_{*} K^{-1} K_{*}^{T}$.

Based on the above GP regression scheme, a Gaussian process classifier (GPC) can be obtained by mapping $f_{*}$ on a sigmoid function, $\pi$, such as the logistic function; i.e., $\pi_{*}=\pi\left(f_{*}\right)=\Phi\left(y_{*}\right)$. An expected mean value of the probability of class membership $\overline{\pi_{*}}$ is expressed as

$$
\overline{\pi_{*}}=\int \pi\left(f_{*}\right) p\left(f_{*} \mid f\right) d f_{*}=\Phi\left(\frac{\bar{y}_{*}}{\sqrt{1+\operatorname{var}\left(y_{*}\right)}}\right)
$$

The GPC provides a prediction to describe building occupant behavior probabilistically with little prior information. The GPC is also efficient at predicting continuous time-series data of unknown occupant activities. For supervised GP modeling, building room designs with different types of space occupancy were generated to create a dataset. As Figure 6 shows, seven features representing space geometry and distances between groups $\left(x_{p 1} \sim x_{p}\right)$ were scaled to [0,1] and matched with binary classification labels (0: not occupiable, 1: occupiable).

On top of this, a simple space transition rule can then be applied. It is assumed that each agent decides whether to stay or to leave at any one time step. Then, we have a state space $\Omega$ with two labels such that $\Omega=\{1$ : stay in the room, 2: leave the room $\}$. Introducing the probability of a transition pair based on a hypothesis, a matrix for occupancy determination $(\mathbf{A})$ can be prepared such that $\mathbf{A}=\left(\mathrm{a}_{i j}\right)=$ $[0.75,0.25 ; 0.5,0.5]$, where $\mathrm{a}_{i j}$ is the probability of an agent to be in state $i$ after being in state $j$. Combining above rules and model parameters, this eventually characterizes a sort of simple "model-based reflex agent" [17]. According to spatial and environmental information, agents' perceptual activities to maintain specific occupancy states are driven by the GPC model. Unobserved aspects of occupancy are reflected with the establishment of the AI model. The whole ABM scheme is illustrated in Figure 7. 


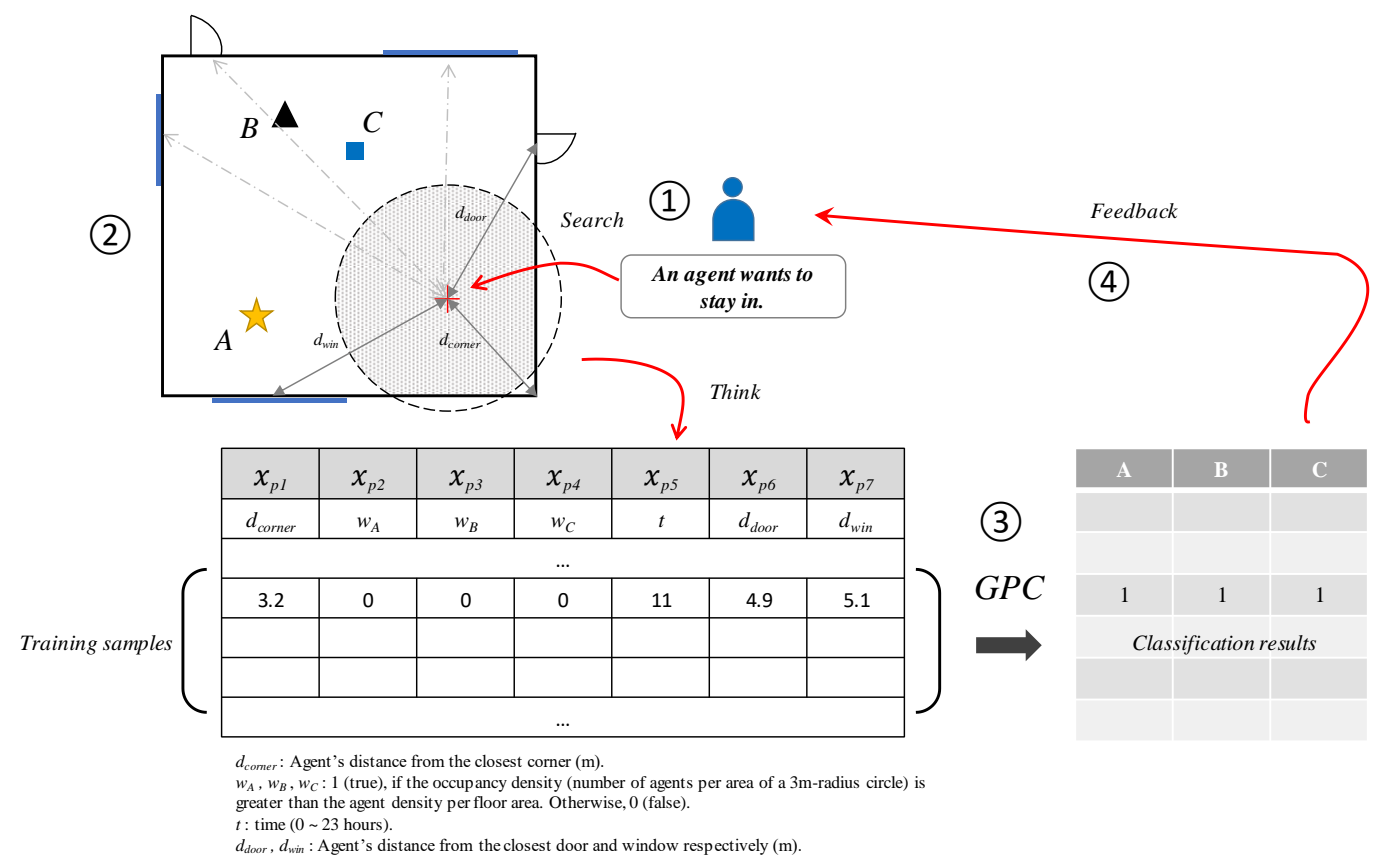

Figure 6. Agents' behavior rule of room occupancy and data format for GP.

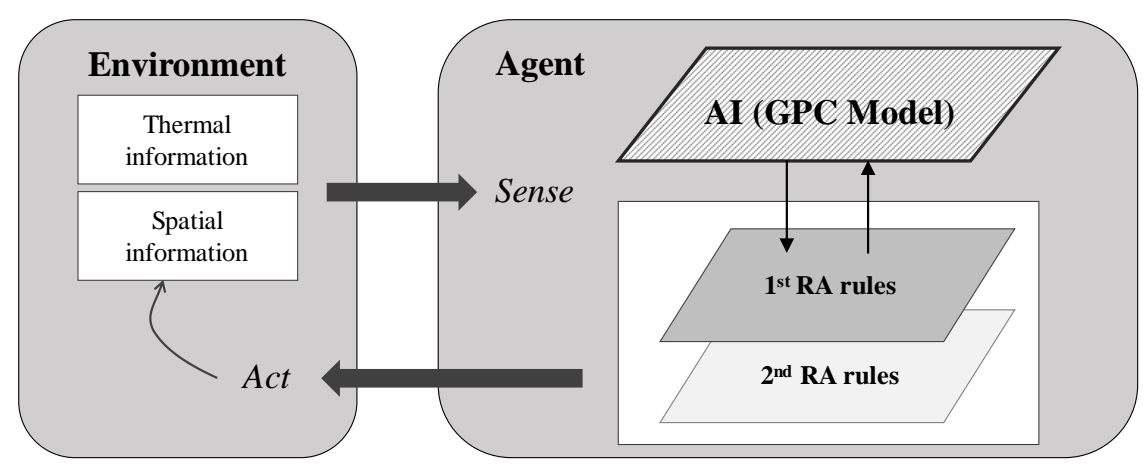

Figure 7. Developed ABM scheme: simple model-based agents.

\section{Test Simulation Results and Discussion}

\subsection{Gaussian Process Prediction Results}

The GPC was integrated within the VUI through a Python editor, using the Python machine learning library, scikit-learn ${ }^{\mathrm{TM}}$ 0.20.3. A GPC GH module is triggered every simulation hour through BCTVB. To develop the GPC, a training dataset based on the agent rule was created and tested with a simple random building plan. Figure 8 presents the trained GPC's test results and the status of agents' space recognition visually mapped over the building plan. Figure 8a represents a situation with a single agent of each group in the space, while Figure $8 \mathrm{~b}$ shows a crowded situation with the agents. These results reveal that the ABM behavior rule was successfully implemented through the GPC model. 

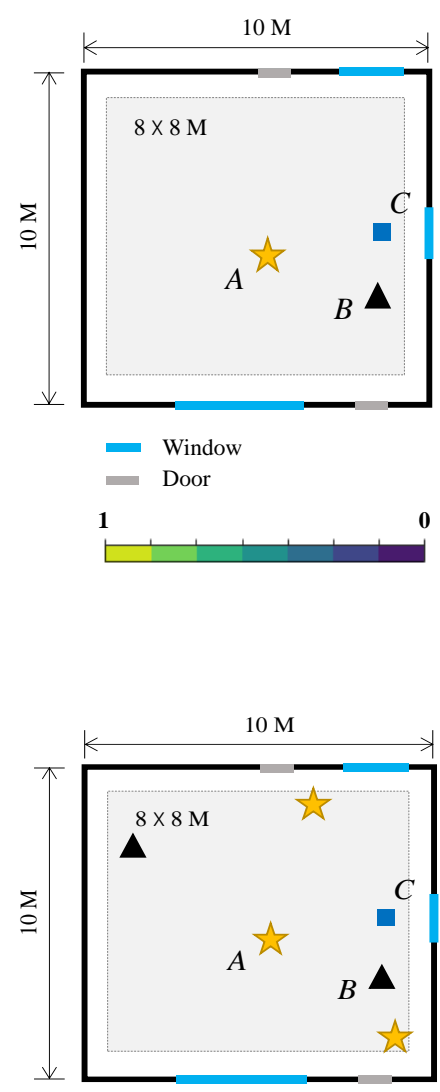

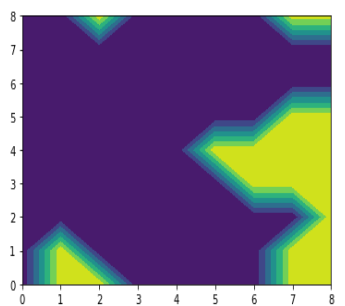

$\mathrm{A}(10: 00 \mathrm{AM})$

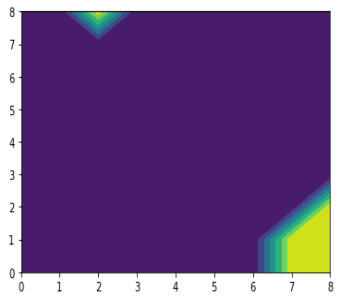

A (2:00 PM)

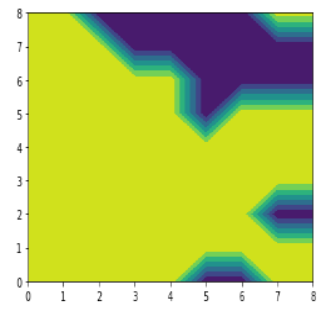

B (10:00 AM)

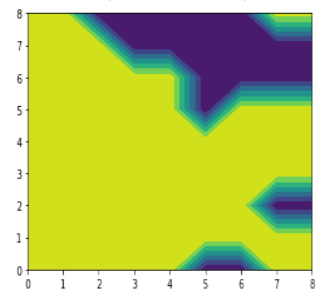

B (2:00 PM)

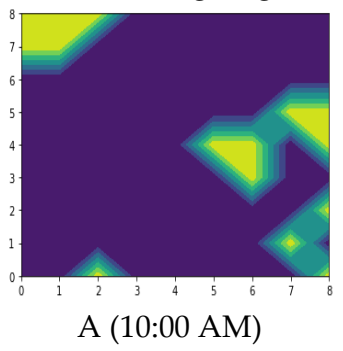

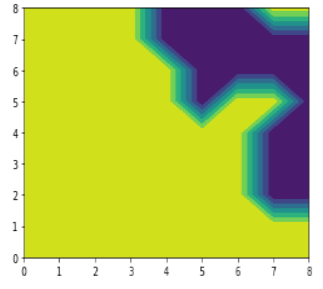

B (10:00 AM)

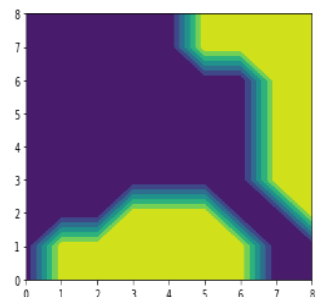

C (10:00 AM)

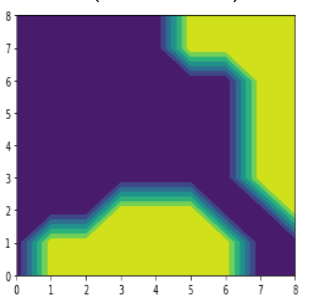

$\mathrm{C}(2: 00 \mathrm{PM})$

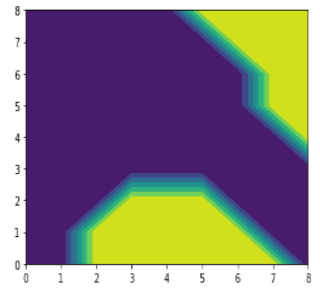

C (10:00 AM)

(b) Mixed situation

Figure 8. Predicted potential move.

\subsection{Visualized Model Outcome: Generation of Building Form and Space Occupancy}

In the visualization through GH, the geometry's surface color changes depending on room temperature; meanwhile, agents appear in Rhino in different colors according to their groups (blue: Group A; pink: Group B; green: Group C) for every discrete time step (Figure 9; Figure 10). Once a user draws a planar line/curve to design a space, a 3D building model with random window/door designs is generated and the ABM simulation is executed. During simulation and optimization, agent movement and geometry changes occur simultaneously, maintaining design constraints and ABM rules. At the initial stage, human figures are randomly spread out over the building floor within a space outline, and their positions are recorded in the ABM memory.
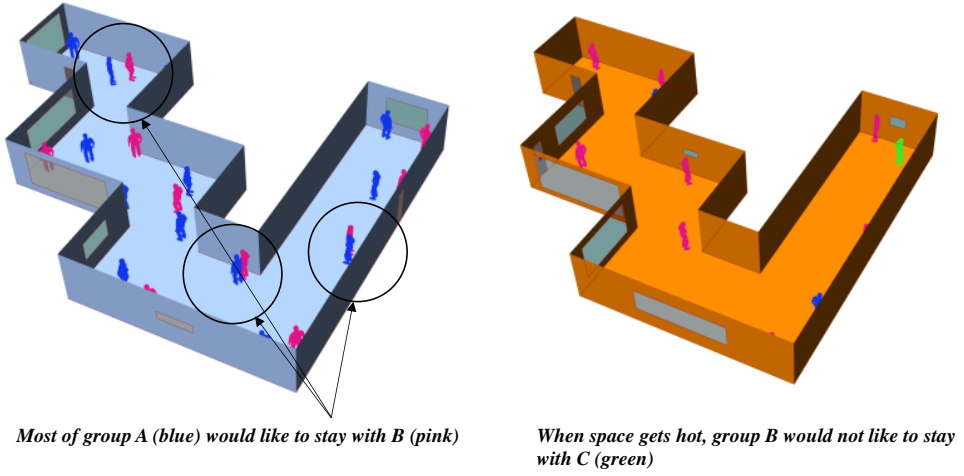

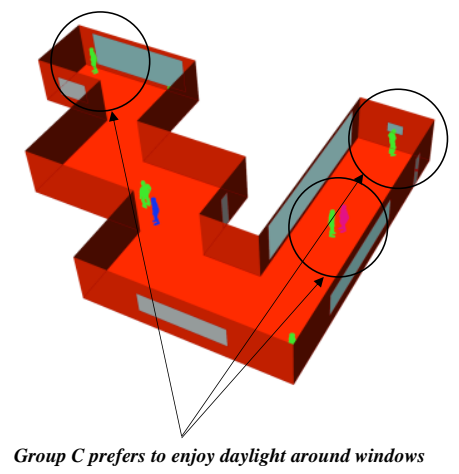

Group C prefers to enjoy daylight around windows

Figure 9. Change in room occupancy according to agent rules. 

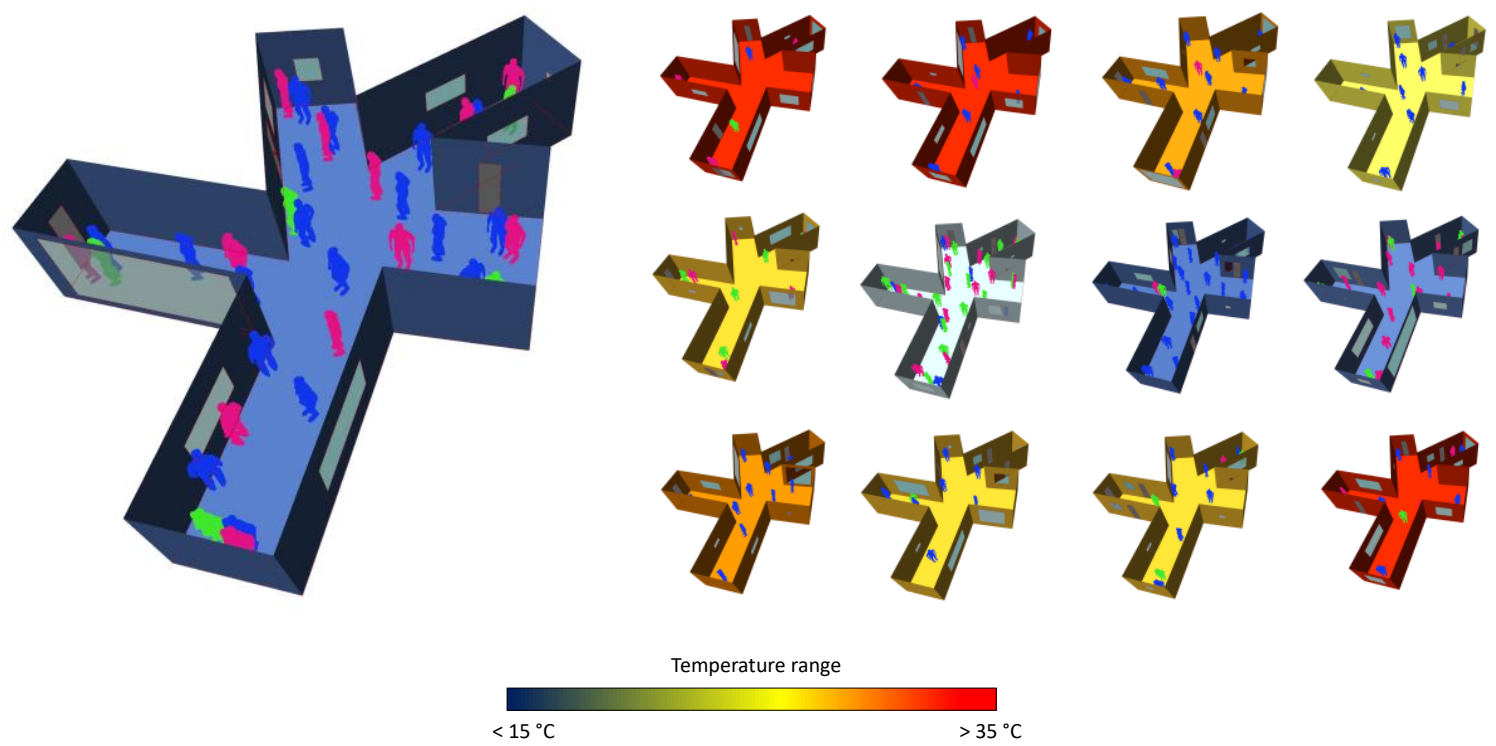

Figure 10. Visualized adaptive geometry in automated optimization process.

\subsection{Analysis of BPS Results}

The results of EP simulation (space (room) temperature and energy use) are displayed on a graph dashboard in the VPL interface (Figure 2) to enable the user to monitor the dynamic ABM simulation process. As a pilot test, ABM was simulated with the geometry shown in Figure 10. Like any public space, this space has no specific function, and the agent rules only govern how to use the space. The total floor area is $750.58 \mathrm{~m}^{2}$, and the number of agents in each group was set to 25 so that the maximum occupancy load would not exceed $10 \mathrm{~m}^{2}$ per person, which is the limit for a typical office. To test a space's adaptability under extreme conditions, the simulation period was set to $24 \mathrm{~h}$ during the day of summer solstice (21 June). Figure 11; Figure 12 present the test results. Figure 11a shows large fluctuations of space occupancy due to the GPC and the agents' stochastic transition rule. The average outdoor temperature in the morning and during the nighttime was around $27.6^{\circ} \mathrm{C}$, while the unconditioned room temperature reached $4-5{ }^{\circ} \mathrm{C}$ higher than this. During system operation (S.1), it was possible to identify variations in the thermostat set points according to agent rules (R.1 6) and scenarios. As a thermostat setting changes, room temperature dynamically changes at each time step. ABM does not provide a single solution-instead, due to its randomness, there are as many solutions as the number of simulation runs. Figure $11 \mathrm{~b}$ plots four different results of ABM simulation. In Figure 12, compared to constant thermostat control (non-ABM), ABM demonstrates that active occupant engagement can ensure energy-saving potential with flexible system operation. While the simulation result only considering variable occupancy (gray line in Figure 12) does not show a major difference, the end energy use of ABM simulation noticeably increased from $0.24 \mathrm{GJ}\left(0.32 \mathrm{MJ} / \mathrm{m}^{2}\right)$ to 0.32 GJ $\left(0.43 \mathrm{MJ} / \mathrm{m}^{2}\right)$. Although the occupant-driven operation did not lead to energy reduction in this case, this result indicates that energy-conscious behavior would benefit building energy use. Moreover, the suggested interface will be helpful in testing dynamic energy performance in advance at any stage during design. 


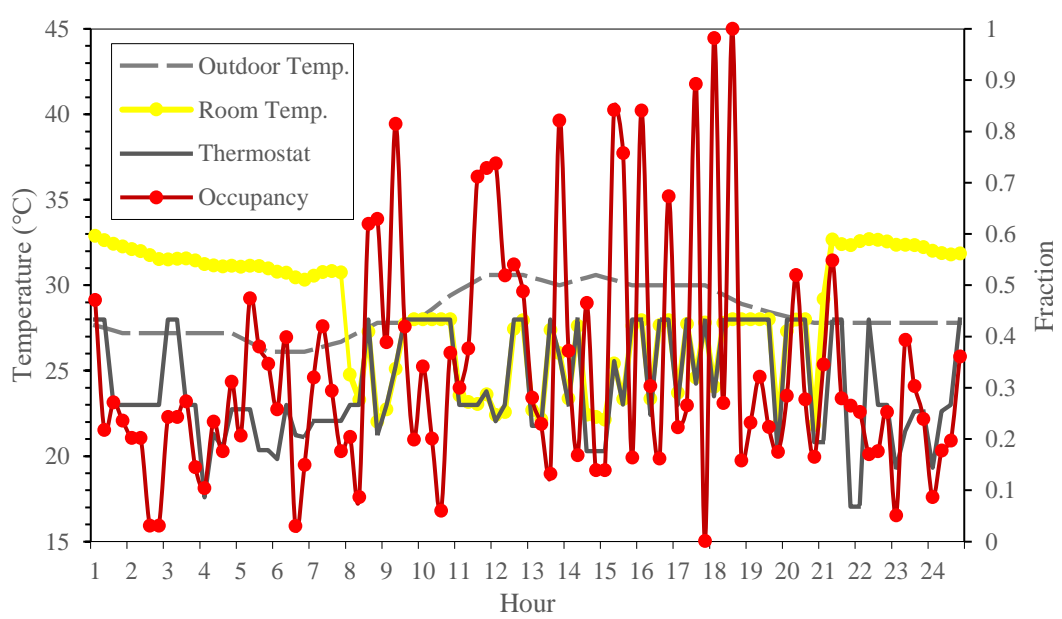

(a)

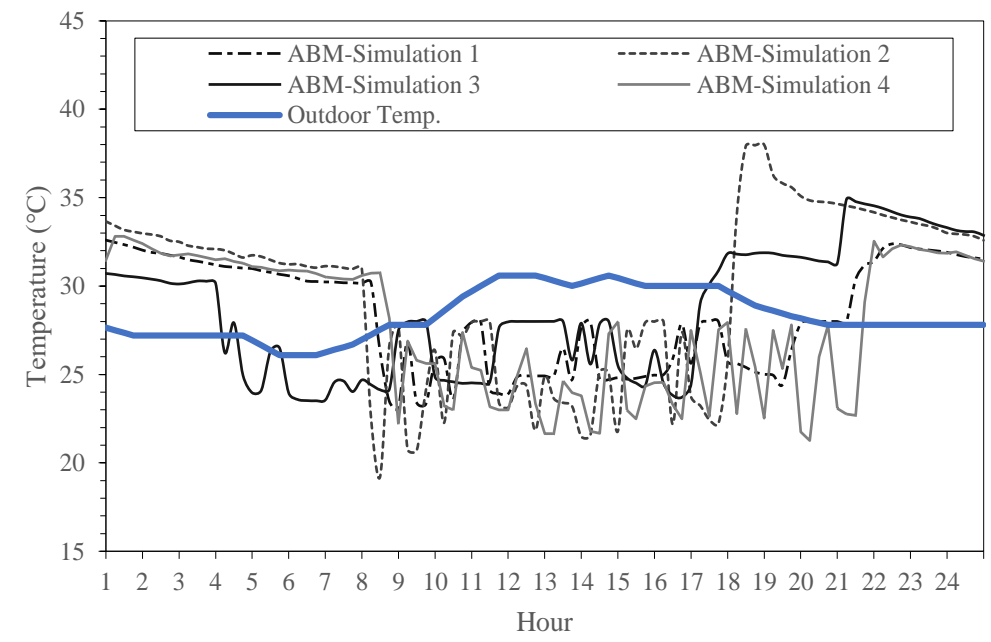

(b)

Figure 11. ABM simulation results: (a) space occupancy and temperature; (b) temperature variations of different simulation runs.

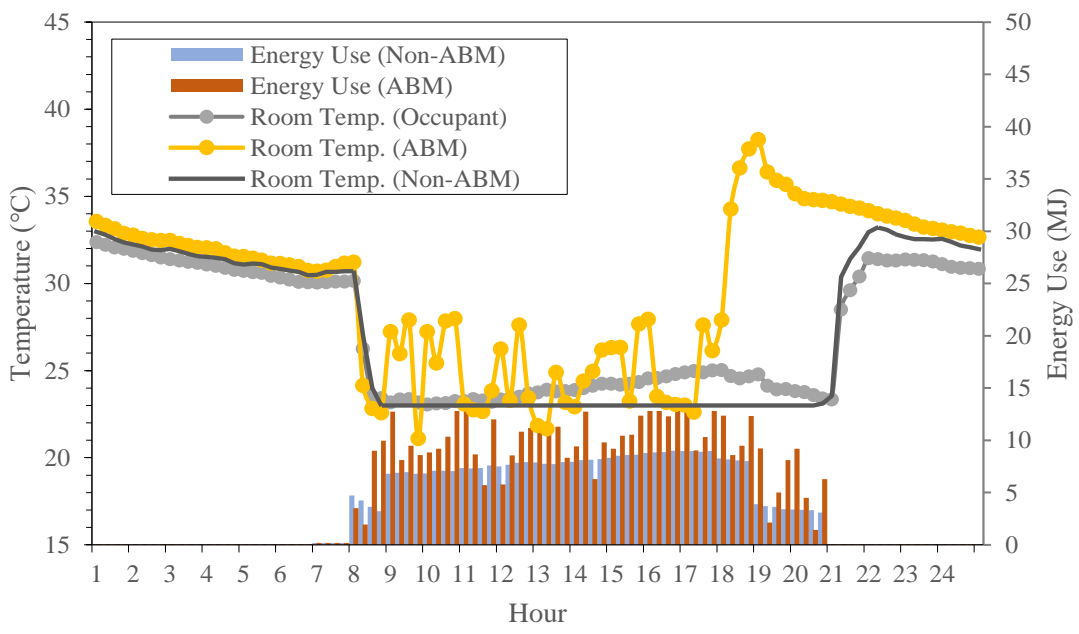

Figure 12. Comparison of $\mathrm{ABM}$ and non-ABM simulation. 


\section{Concluding Remarks}

Currently, advanced simulation techniques regarding human behavior call for a transformative approach to sustainable building design methodology. This is because conventional approaches to sustainable building design primarily emphasize time-tested evidence and in-depth engineering pursuits that are invisible to architects. Although early design phases must be sufficiently informed by real-world parameters and design concerns, the existing tools and methods are not fully supportive for architectural practice.

An important way to make PBD more accurate is to couple the process of single-purpose simulation with real-world parameters to strengthen the responsive (feedback) mechanism between a digital environment and actual representation. Adding "real" properties to BPS will not only greatly improve the reliability of simulation outcomes but also help users to envision new possibilities of BPS application to environmental architectural design — for example, real-time accessibility and prediction of building conditions and behavior, building operation resilience, or preemptive building diagnosis.

In order to propose a more interactive and dynamic PBD process, this study suggested a design-oriented multi-dimensional PBD system using digital building modeling coupled with artificial behavior imitation and simulated data analytics. To this end, the study has pioneered the dynamic integration of ABM and BPS through the parametric interfacing of an automated design process using GH as a VPL, demonstrating that coupling PBD with human behavior can serve as a novel architectural design process. The study's results showed that this ABM framework can significantly make design more intelligent and strengthen the power of simulated worlds beyond mere technical merits. The ABM-based, decision-support interface proposed herein can help designers easily access building thermal information and quickly explore various design options through seamless automation. Moreover, the visualized thermal environment and occupant behavior in a given space can focus our attention on feedback loops between a built form and usage patterns as well as the importance of human-building interactive design to achieve sustainability.

The study's proposed ABM is based on building users' realistic attributes, but the behavior rules employed here were hypothetical. Thus, the different agent scenarios must be validated through comparison with actual social human interaction. To improve data quality and outcome precision, an in-depth analysis of actual building use patterns is necessary. Further studies might employ questionnaire surveys or monitoring of human activities to develop a more robust agent model. Tether-free data communication, sensing of physical systems, remote visualization, and self-adjustment in data transmission related to cyber-physical system (CPS) integration can also be taken into consideration in future research.

Funding: This work was supported by a grant from the National Research Foundation of Korea (NRF), funded by the Korean government (MSIT) (No. NRF-2019R1A2C100913012).

Conflicts of Interest: The authors declare no conflict of interest.

\section{References}

1. Solmaz, A.S. A Critical Review on Building Performance Simulation Tools. Int. J. Sustain. Trop. Des. Res. Prac. 2019, 12, 7-20.

2. Brause, C.; Ford, C.F.; Olsen, C.; Ripple, J.; Uihlein, M.S.; Zarzycki, A.; Vonier, P. Simulations: Modeling, Measuring, and Disrupting Design, TAD; Taylor \& Francis Group, LLC.: New York, NY, USA, 2017.

3. Yi, H.; Yi, Y.K. Performance Based Architectural design optimization: Automated 3D space Layout using simulated annealing. In Proceedings of the 2014 ASHRAE-IBPSA Building Simulation Conference, Atlanta, GA, USA, 25 August 2014; pp. 292-299.

4. Lin, S.E.; Gerber, D.J. Designing-in performance: A framework for evolutionary energy performance feedback in early stage design. Autom. Constr. 2014, 38, 59-73. [CrossRef]

5. Lee, E.A. Heterogeneous Modeling. In System Design, Modeling, and Simulation Using Ptolemy II, 1st ed.; Ptolemaeus, C., Ed.; Ptolemy: Berkeley, CA, USA, 2014. 
6. Sebastian, R. Changing roles of the clients, architects and contractors through BIM. Eng. Constr. Arch. Manag. 2011, 18, 176-187. [CrossRef]

7. Macdonald, I.; Strachan, P. Practical application of uncertainty analysis. Energy Build. 2001, 33, $219-227$. [CrossRef]

8. de Wit, S. Uncertainty in building simulation. In Advanced Building Simulation; Malkawi, A., Augenbroe, G., Eds.; Spon Press: New York, NY, USA, 2003.

9. Yi, H. User-driven automation for optimal thermal-zone layout during space programming phases. Arch. Sci. Rev. 2016, 59, 279-306. [CrossRef]

10. Gomes, C.; Thule, C.; Broman, D.; Larsen, P.G.; Vangheluwe, H. Co-simulation: State of the art. arXiv 2017, arXiv:abs/1702.00686.

11. Hansen, J. Integrated building airflow simulation. In Advanced Building Simulation; Malkawi, A., Augenbroe, G., Eds.; Spon Press: New York, NY, USA, 2003; pp. 87-118.

12. Wetter, M. Co-simulation of building energy and control systems with the Building Controls Virtual Test Bed. J. Build. Perform. Simul. 2011, 4, 185-203. [CrossRef]

13. Hong, T.; Sun, H.; Chen, Y.; Taylor-Lange, S.C.; Yan, D. An occupant behavior modeling tool for co-simulation. Energy Build. 2016, 117, 272-281. [CrossRef]

14. Kensek, K.M. Teaching Visual Scripting in BIM: A case study using a panel controlled by solar angles. J. Green Build. 2018, 13, 113-138. [CrossRef]

15. Aksamija, A. BIM-Based Building Performance Analysis: Evaluation and simulation of design decisions. In Proceedings of the 17th Biennial ACEEE Conference on Energy Efficiency in Buildings, Pacific Grove, CA, USA, 12 August 2012.

16. Jeong, W.; Kim, J.B.; Clayton, M.J.; Haberl, J.S.; Yan, W. A framework to integrate object-oriented physical modelling with building information modelling for building thermal simulation. J. Build. Perform. Simul. 2016, 9, 50-69. [CrossRef]

17. Russell, S.; Norvig, P. Artificial Intelligence: A Modern Approach; Prentice-Hall, Inc.: Upper Saddle River, NJ, USA, 1995.

18. Wilensky, U.; Rand, W. An Introduction to Agent-Based Modeling: Modeling Natural, Social, and Engineered Complex Systems with NetLogo; MIT Press: Cambridge, MA, USA, 2015.

19. Epstein, J.M.; Axtell, R. Growing Artificial Societies: Social Science from the Bottom Up; MIT Press: Cambridge, MA, USA, 1996.

20. Bonabeau, E. Agent-based modeling: Methods and techniques for simulating human systems. Proc. Natl. Acad. Sci. USA 2002, 99, 7280-7287. [CrossRef] [PubMed]

21. Micolier, A.; Taillandier, F.; Taillandier, P.; Bos, F. Li-BIM, an agent-based approach to simulate occupant-building interaction from the Building-Information Modelling. Eng. Appl. Artif. Intell. 2019, 82, 44-59. [CrossRef]

22. Lee, Y.S.; Malkawi, A.M. Simulating multiple occupant behaviors in buildings: An agent-based modeling approach. Energy Build. 2014, 69, 407-416. [CrossRef]

23. Penn, A.; Turner, A. Space syntax based agent simulation. In Pedestrian and Evacuation Dynamics; Schreckenberg, M., Sharma, S.D., Eds.; Springer: Berlin, Germany, 2002; pp. 99-114.

24. Cheliotis, K. An agent-based model of public space use. Comput. Environ. Urban Syst. 2020, 81, 101476. [CrossRef]

25. Gao, Y.; Gu, N. Complexity, Human Agents, and Architectural Design: A Computational Framework. Des. Princ. Pract. 2009, 3, 115-126. [CrossRef]

26. Andrews, C.J.; Yi, D.; Krogmann, U.; Senick, J.A.; Wener, R.E. Designing Buildings for Real Occupants: An Agent-Based Approach. IEEE Trans. 2011, 41, 1077-1091. [CrossRef]

27. Koutsolampros, P.; Sailer, K.; Varoudis, T. Partitioning indoor space using visibility graphs: Investigating user behavior in office spaces. In Proceedings of the 4th International Symposium Formal Methods in Architecture, Porto, Portugal, 2 April 2018.

28. Chen, L. Agent-based modeling in urban and architectural research: A brief literature review. Front. Archit. Res. 2012, 1, 166-177. [CrossRef]

29. Breslav, S.; Goldstein, R.; Tessier, A.; Khan, A. Towards Visualization of Simulated Occupants and their Interactions with Buildings at Multiple Time Scales. In Proceedings of the Symposium on Simulation for Architecture and Urban Design (SimAUD 2014), Tampa, FL, USA, 14 April 2014. 
30. Nagy, D.; Villagi, L.; Stoddart, J.; Benjamin, D. The Buzz Metric: A Graph-based Method for Quantifying Productive Congestion in Generative Space Planning for Architecture. TAD 2017, 1, 186-195. [CrossRef]

31. Figueroa, M.; Putra, H.C.; Andrews, C.J. Preliminary Report: Incorporating Information on Occupant Behavior into Building Energy Models; The Center for Green Building at Rutgers University for the Energy Efficient Buildings Hub: Philadelphia, PA, USA, 2014.

32. Hong, T.; Taylor-Lange, S.C.; D'Oca, S.; Yan, D.; Corgnati, S.P. Advances in research and applications of energy-related occupant behavior in buildings. Energy Build. 2016, 116, 694-702. [CrossRef]

33. D'Oca, S.; Hong, T.; Langevin, J. The human dimensions of energy use in buildings: A review. Renew. Sustain. Energy Rev. 2018, 81, 731-742. [CrossRef]

34. Janda, K. Buildings Don't Use Energy: People Do. Archit. Sci. Rev. 2011, 54, 15-22. [CrossRef]

35. Yi, H. A biophysical approach to the performance diagnosis of human-building energy interaction: Information (bits) modeling, algorithm, and indicators of energy flow complexity. Environ. Impact Assess. Rev. 2018, 72, 108-125. [CrossRef]

36. Gophikrishnan, S.; Topkar, V.M. Attributes and descriptors for building performance evaluation. HBRC J. 2017, 13, 291-296. [CrossRef]

37. Yi, H. Rapid simulation of optimally responsive façade during schematic design phases: Use of a new hybrid metaheuristic algorithm. Sustainability 2019, 11, 2681. [CrossRef]

38. Sakoi, T.; Tsuzuki, K.; Kato, S.; Ooka, R.; Song, D.; Zhu, S. Thermal comfort, skin temperature distribution, and sensible heat loss distribution in the sitting posture in various asymmetric radiant fields. Build. Environ. 2007, 42, 3984-3999. [CrossRef]

39. Çengel, Y.A.; Ghajar, A.J. Heat and Mass Transfer: Fundamentals \& Applications, 4th ed.; McGraw-Hill: New York, NY, USA, 2011.

40. Oğulata, R.T. The Effect of Thermal Insulation of Clothing on Human Thermal Comfort. Fibres Text. East. Eur. $2007,15,67-72$.

(C) 2020 by the author. Licensee MDPI, Basel, Switzerland. This article is an open access article distributed under the terms and conditions of the Creative Commons Attribution (CC BY) license (http://creativecommons.org/licenses/by/4.0/). 